\title{
UNIFICACIÓN DE JURISPRUDENCIA, PRECEDENTE JUDICIAL Y APLICACIÓN DIRECTA DE LA CONSTITUCIÓN
}

\author{
EDUARDO YÁÑEZ MONJE* \\ Universidad de Chile
}

\begin{abstract}
RESUMEN: Este artículo niega que el actual recurso de unificación de jurisprudencia deba ser entendido como un mecanismo que incorpora a la legislación chilena el precedente judicial, por ser contrario a los postulados propios del estado de derecho tradicional. Su razonamiento radica en una premisa dogmático-política, esto es, el contenido de las cláusulas constitucionales debe ser fijado mediante reglas -formuladas deliberación política mediante-, y no dejarse a un cuerpo de elite como lo es la Corte Suprema, a costa de apropiarse de una discusión propiamente política. Dicha apropiación, unida a un mecanismo de precedente obligatorio, dejaría al juez en una situación equiparable a la del legislador.
\end{abstract}

Palabras clave: predecibilidad judicial, unificación de jurisprudencia, derechos fundamentales, política, ética, antagonismo.

\begin{abstract}
This article denies that the current recourse of unification of jurisprudence must be understood as a .mechanism that incorporates to the Chilean legislation the judicial precedent, as being contrary to the proper postulates of a traditional rule of law state. Its reason rests on a dogmatic-politic premise, that is, the content of the constitutional provisions must be set by rules, made by political deliberation, and not left to an elite group as it is the Supreme Court, at the cost of appropriating a strictly political discussion. This appropriation, combined with a mechanism of binding precedent, would let the judge in a situation comparable to that of the legislature.
\end{abstract}

Key words: judicial predictability, unification of jurisprudence, fundamental rights, politics, ethics, antagonism.

\section{INTRODUCCIÓN}

Me propongo discutir una idea corriente en la cultura jurídica, relativa a la idea de predecibilidad judicial y obligatoriedad de los precedentes de los tribunales superiores de justicia. Se ha estimado urgente establecer un mecanismo que asegure la igualdad ante la ley frente a decisiones potencialmente discrepantes de los tribunales, cuando se trata de interpretar conceptos esencialmente controvertidos ${ }^{1}$ como los derechos fundamentales, y aplicar-

\footnotetext{
"Ayudante del Departamento de Derecho del Trabajo y de la Seguridad Social, Facultad de Derecho, Universidad de Chile.

${ }^{1}$ Para utilizar el lenguaje de la profesora ACCATINO, Daniela. "Los afanes de la Interpretación Constitucional", en: Revista Derecho y Humanidades $\mathrm{N}^{\circ} 12$, p. 35. Santiago: Universidad de Chile, 2006. En dicho artículo la académica de la Universidad Austral se propone discutir, en torno a dos concepciones de la interpretación constitucional, una teoría descripriva y una teoría normativa. Sin perjuicio de que al mismo tiempo reconoce algo que es fundamental en el trabajo que me convoca ahora. "Esta interpretación sobre las disposiciones sobre derechos fundamentales, que determina en nuestra práctica jurídica un grado de constitucinalización que no encuentra equivalente en otros sistemas jurídicos, presupone una peculiar concepción del Estado de Derecho. Una concepción en que el imperio del derecho no es entendido como la sujeción a las reglas generales establecidas por la ley, a la que le corresponde determinar el punto en que la libertad de uno lesiona la libertad del otro, sino como la sujeción a las disposiciones particulares y concretas a través de los cuales los jueces determinan el alcance de nuestros derechos", p. 42.
} 
los al caso concreto. Pretendo discutir este tema por dos hechos fundamentales; a) por una parte la recepción de la doctrina de la aplicación directa de la Constitución en el Derecho del Trabajo; y b) la existencia de un nuevo recurso en la esfera del derecho procesal del trabajo, el recurso de unificación de jurisprudencia, cuyo conocimiento corresponde a la Corte Suprema, y que procede contra la sentencia de la Corte de Apelaciones respectiva que resuelve un recurso de nulidad, cuando existen dos o más sentencias con un contenido discrepante relativo a la materia de derecho sobre la que trata la sentencia que resuelve la nulidad.

El objeto del recurso de unificación de jurisprudencia es, desde luego como su nombre lo dice, la unidad de la interpretación de la ley por parte de los tribunales, debiendo fijar dicha unidad precisamente la Corte Suprema. Se opina que, si bien no existe ninguna norma que obligue al tribunal inferior a fallar conforme a un precedente fijado por la Corte Suprema, el mandato de la igualdad ante la ley obligaría de igual modo a fallar conforme a la jurisprudencia ya sentada por los tribunales ${ }^{2}$, y de ese modo mantener al mismo tiempo la seguridad jurídica y la coherencia del sistema jurídico ${ }^{3}$. Al contrario, mi opinión consiste en que una supuesta obligatoriedad del precedente judicial desplazaría el poder de dar contenido a cláusulas vagas como las que establecen derechos fundamentales, desde el Poder Legislativo -órgano que cuenta con una genuina legitimidad democrática- a los tribunales -que apenas tienen legitimidad democrática de forma indirecta-, sin atender a que dichas cláusulas son precisamente vagas, y fijarles contenido es una tarea esencialmente política que ningún tribunal puede acaparar y pretender objetividad sobre su decisión ${ }^{4}$.

\footnotetext{
2 Pfeffer URquiaga, Emilio. "La introducción del precedente. Un cambio revolucionario en nuestra cultura jurídica", en: Estudios Constitucionales, p. 11. Talca: Centro de Estudios Constitucionales, Universidad de Talca, julio 2006. Llama la atención la afirmación del autor: "se postula incluso que si el valor del precedente encuentra reconocimiento en el artículo $19 \mathrm{~N}^{\circ}$ 2 y 3 de la Carta Fundamental, lo dispuesto en el artículo $3^{\circ}$ del Código Civil en cuanto sienta el principio del valor relativo de las sentencias se encontraría derogado tácitamente". Dado que el abogado Pfeffer no cita a ningún autor en particular al formular dicha afirmación, es porque asumo que debe atribuírsele a él mismo. Establecer que la igualdad ante la ley y el debido proceso hayan derogado tácitamente el efecto relativo de las sentencias, establecido en el artículo $3^{\circ}$ del Código Civil, es una exageración provocada por la doctrina de la aplicación directa de la Constitución.

3 Sobre este punto la literatura es muy abundante: NoGueira AlCALÁ, Humberto. "La Independencia del Poder Judicial: una Condición y Garantía Estructural del Estado Constitucional”, en: Gaceta Jurídica No 329, noviembre 2007. LEGARRE, Santiago y Rivera, Julio César. "Naturaleza y dimensiones del stare decisis", en: Revista Chilena de Derecho, vol. $33 \mathrm{~N}^{\circ} 1$. Santiago: Pontificia Universidad Católica de Chile, 2006. GARRIDO GOMEZ, María Isabel. "La predecibilidad de las decisiones judiciales", en: Ius et Praxis. $15 \mathrm{~N}^{\circ}$ 1, Talca, Universidad de Talca. Bordalf SalamanCA, Andrés. "La unidad en la interpretación jurisdiccional de los derechos fundamentales: una tarea pendiente en el derecho chileno", en: Revista Chilena de Derecho, vol. 43, $\mathrm{N}^{\circ}$ 3. Santiago: Pontificia Universidad Católica de Chile, año 2007. Son solo algunos.

${ }^{4}$ En concreto, ya había utilizado estos argumentos para desestimar a priori una eventual decisión del Tribunal Constitucional en torno al concepto de empresa de nuestro del Código del Trabajo. "La omisión a una individualidad legal determinada puede generar -según los parlamentarios recurrentes de inconstitucionalidad- un serio perjuicio a la libertad económica, libertad de contratación, libertad de trabajo y derecho de propiedad a las empresas presuntamente relacionadas, pues algunas empresas se pueden ver obligadas a asumir responsabilidades respecto de trabajadores en virtud de actos jurídicos de los cuales nunca formaron parte. Sin embargo, por otro lado, se considera un imperativo ético salvaguardar los derechos de los trabajadores, y mantenerlos a salvo del desmembramiento jurídico. Existía el temor de que el Tribunal Constitucional cerrara el debate, o más aún, que lo declarara constitucional en la Ley de Subcontratación, lo que reafirmaría la idea de que la individualidad legal determinada se mantuviera vigente en el concepto de empresa en la legislación laboral en general -como argumento a contrario sensu-. Sin embargo llama la atención, que siendo una discusión acerca de la prevalencia de la libertad empresarial o de prerrogativas laborales de los trabajadores, deba ser decidida por un organismo jurisdiccional, en circunstancias que posee la fisonomía de una discusión estrictamente política, respecto de la cual ningún tribunal está legitimado a decidir. Los conceptos
} 
Evidentemente, la respuesta a la pregunta que nos planteamos no puede ser dada desde el derecho, no es precisamente una pregunta jurídica, de lo contrario, bastaría con traer a colación el artículo 483-C del Código del Trabajo que establece que el fallo que se pronuncie sobre el recurso -de unificación de jurisprudencia- solo tendrá efecto respecto de la causa respectiva, y así se despeja -jurídicamente- la duda que se plantea. Sin embargo, es más bien una pregunta acerca del derecho, y cómo debe ser concebido para garantizar el autogobierno democrático. Por lo tanto, la respuesta a la pregunta que da título a este trabajo debe ser contestada partiendo de una premisa relativa a una determinada concepción de la política. En consecuencia, debemos partir por ahí.

\section{LA POLÍTICA COMO OPOSICIÓN}

"Hay una forma particular de leer y hacer respetar una constitución política que denomino la lectura moral"5, parte señalando Dworkin en La lectura Moral y la Premisa Mayoritarista. Esta lectura moral es caracterizada por Dworkin como una práctica judicial imperante -pero implícita- en la historia institucional de la judicatura de los Estados Uni$\operatorname{dos}^{6}$. La lectura moral de la Constitución implica que los jueces deben interpretar las cláusulas constitucionales como si se trataran de principios morales sobre la decencia política y de la justicia ${ }^{7}$. Dichos principios deben servir de guía al juez por sobre todo en aquellos casos considerados dificiles ${ }^{8}$, en que el modelo de subsunción de carácter estrictamente positivista queda superado.

Estos principios morales nacen como respuesta al problema que Dworkin identifica en el positivismo jurídico -tomando como referencia a H.L.A. Hart-, pues el sistema jurídico, en tanto sistema cerrado, no da respuesta satisfactoria a aquellos casos que no pueden subsumirse en las reglas que forman parte de dicho sistema9. Para una mejor explicación, de acuerdo a Hart el sistema jurídico se compone de reglas primarias y secundarias ${ }^{10}$; las normas primarias son las que mandan, prohíben o permiten una determinada conducta ${ }^{11}, y$ que son aceptadas por un grupo determinado de personas como normas de conducta obli-

\footnotetext{
constitucionales son por sí mismo incontrovertibles, nadie duda que las empresas deban tener libertad, ni nadie duda al mismo tiempo que los trabajadores, parte débil de una relación jurídica, deba ser protegida, pero esos conceptos deben ser llenados de contenido con una concepción particular de lo que ese concepto debe querer decir, y esa concepción-eminentemente política- debe ser suministrada por el órgano que posee la legitimidad democrática para hacerlo, esto es, los parlamentos. Pensar de otra manera, nos llevaría a otorgarle competencia al Tribunal para que decida por nosotros las políticas contra la delincuencia o que elija el sistema de salud que más conviene a los súbditos del reino del Tribunal Constitucional". YáñEZ MONJE, Eduardo. "Comentarios acerca del concepto de empresa en el Código del Trabajo", en: Revista Chilena de Derecho del Trabajo y de la Seguridad Social, vol. 1. $\mathrm{N}^{\circ}$ 1, pp. 133 y ss. Santiago: Universidad de Chile, 2010.

${ }^{5}$ DwORKIN, Ronald. "La lectura moral y la premisa mayoritarista", en: KOH, Harold Hongju y SLYE, Ronald C. (comp.). Democracia Deliberativa y Derechos Humanos. Editorial Gedisa, 2004, p. 101.

${ }^{6}$ DWORKIN, Ronald, "La'lectura moral... (n. 5), pp. 101-105.

7 DwORKIN, Ronald, "La lectura moral... (n. 5), p. 101.

${ }^{8}$ Ver DWORKIN, Ronald. Los Derechos en Serio. Barcelona: Editorial Ariel S.A., año 1999, pp.146-206.

${ }^{9}$ Dworkin, Ronald, Los Derechos... (n. 8), pp. 61-145.

${ }^{10}$ Ver la explicación de DworkIN, Ronald, Los Derechos... (n. 8), pp. 69-71.

${ }^{11}$ Por usar el lenguaje del artículo 1 de nuestro Código Civil.
} 
gatoria ${ }^{12}$. Las normas secundarias son aquellas que establecen los procedimientos a través de los cuales se generarán las normas primarias de conducta, las que, por ser producidas por estas reglas secundarias, se considerarán formalmente obligatorias. Estas reglas secundarias se remiten a una regla secundaria fundamental, que se denomina regla de reconocimiento. Dicha regla de reconocimiento será -o puede ser en general- una Constitución política ${ }^{13}$.

Este modelo de reglas primarias generadas por reglas secundarias, posee una importante limitación. Dicha limitación consiste en la incapacidad de responder de manera coherente con el mismo sistema a aquellos casos que no están circunscritos en regla alguna formalmente generada. Esta limitación es vista por Hart como inevitable, pues el potencial de indeterminación es consustancial al lenguaje, y ello redunda en que las normas tengan irremediablemente una textura abierta ${ }^{14}$. De este modo, dado que el juez tiene la obligación de resolver el caso puesto a su conocimiento, debe usar su discreción ${ }^{15}$. Esta discreción es caracterizada por Dworkin como una discreción en sentido fuerte, en que ante la imposibilidad de subsumir el caso en una norma formalmente generada ${ }^{16}$, el juez pueda decidir sin sujeción a estándares que puedan reconducirse -al menos implícitamente- al propio sistema jurídico, sino que decida creando una regla para ese caso concreto, en forma absolutamente libre. Esta discreción en sentido fuerte debe distinguirse de una discreción en sentido débil, en que el juez puede usar en todo caso su discreción, pero siempre y cuando esté sujeto a los parámetros que la propia norma que le otorga competencia para decidir establezca ${ }^{17}$. Esta última no es la acepción que utiliza el positivismo para referirse a la discreción del juez, sino el anterior, la discreción en sentido fuerte. El juez debe fallar conforme al sentido que escoja, no porque exista una norma que resuelva el caso -la que él debe crear usando su discreción-, sino por que las partes tienen un derecho preexistente a ganar el juicio ${ }^{18}$.

Esta visión del positivismo sobre el papel en último término creador del juez, es rechazada por Dworkin, quien plantea una objeción democrática a la tesis de la discreción en sentido fuerte, pues esta hace caso omiso del principio de la vinculación del juez a la ley, establecida como manifestación concreta de la división de poderes. En tal situación, jueces sin responsabilidad política directa, estarían creando normas y aplicándolas retroactivamente al caso que está conociendo. De esta manera, quien pierda el juicio será castigado por leyes

\footnotetext{
${ }^{12}$ DWORKIN, Ronald, Los Derechos... (n. 8), p. 69.

${ }^{13}$ Ibid.

14 Ibid.

15 Ibid.

${ }^{16}$ Me refiero, en específico, a una norma generada mediante las normas secundarias de Hart.

17 DwORKIN, Ronald, Los Derechos... (n. 8), p. 84. "A veces hablamos de discreción en un sentido débil, simplemente para decir que por alguna razón, las normas que debe aplicar un funcionario no se pueden aplicar mecánicamente, sino que exigen discernimiento. Usamos este sentido débil cuando el contexto todavía no lo aclara, cuando la información básica con que cuenta nuestro auditorio no contiene esa información. Así, podríamos decir: las órdenes recibidas dejaban un amplio margen de discreción al sargento, a alguien que no sabe cuáles eran las órdenes que este había recibido, o que desconoce algo que hacía que las normas fueran vagas o difíciles de llevar a la práctica. $Y$ tendría mucho sentido agregar, como aclaración, que el teniente le había ordenado que formara una patrulla con sus cinco hombres más experimentados, pero que era difícil decidir quiénes eran los más experimentados".

${ }^{18}$ DWORKIN, Ronald, Los Derechos... (n. 8), p. 146.
} 
que no podía conocer, porque efectivamente no existían ${ }^{19}$. Al contario, sostiene Dworkin, siempre existen respuestas correctas para todos los casos, y si bien en un modelo positivista es indudable que no todos los casos podrán ser subsumibles en reglas formalmente generadas, eso no quiere decir que el juez deba crear normas, sino que debe descubrir cuál es la respuesta correcta que ya está contenida en el ordenamiento jurídico en particular, la que si no se puede extraer de reglas primarias de conducta - para usar términos de Hart- debe buscarse en los principios ${ }^{20}$.

Sin embargo, las objeciones democráticas realizadas a la creación judicial del derecho por parte del juez, en la teoría de la discreción judicial en sentido fuerte del positivismo, pueden atacar -análogamente- también la resolución de casos difíciles conforme a principios. Pues, si no existe un procedimiento en particular para discernir cuál es el principio correctamente aplicable a un caso concreto, debe elegir alguno de ellos, y para eso usará la discreción en sentido fuerte al igual que el juez positivista crea una norma no prevista por el legislador. No obstante Dworkin plantea dos tipos de contraargumentos; a) no es cierto que el juez no tenga un procedimiento establecido para discernir cuál es el principio aplicable a cada caso. Siempre existe una respuesta correcta para cada caso y el juez debe descubrirla ${ }^{21}$. No se trata de escoger arbitrariamente entre uno u otro, sino que debe realizarse con ciertas limitaciones, como por ejemplo; el juez no puede hacer valer su propia moralidad en las cláusulas de la constitución, a menos que tenga coherencia con la historia institucional de la judicatura; b) la radicación en el juez de la tarea de deliberar acerca de qué principios morales son aquellos establecidos en el ordenamiento jurídico, no es un ejercicio antidemocrático, como aparenta serlo. Al contrario, el respeto del juez de aquellos principios morales, aun cuando sean contrarios a las leyes refrendadas por la mayoría, constituye el presupuesto y la garantía de la democracia.

\footnotetext{
${ }^{19}$ DWORKIN, Ronald, Los Derechos... (n. 8), p. 150. "La conocida actitud de que la adjudicación de competencia debe estar tan subordinada a la legislación encuentra apoyo a dos objeciones al poder creador de derecho del juez. La primera sostiene que una comunidad debe ser gobernada por hombres y mujeres elegidos por la mayoría y responsables ante ella. Como los jueces, en su mayoría, no son electos, y como en la práctica no son responsables ante el electorado de la manera que lo son los legisladores, el que los jueces legislen parece comprometer esa proposición. La segunda objeción expresa que si un juez legisla y aplica retroactivamente la ley al caso que tiene entre manos, entonces la parte perdedora será castigada no por haber infringido algún deber que tenía, sino un deber nuevo creado después del hecho. Estos dos argumentos se combinan en apoyo a la idea tradicional de que la adjudicación de competencia la juez debe estar tan subordinada a la ley como sea posible. Pero presenta objeciones mucho más poderosas a las decisiones judiciales generadas por directrices políticas que a la generadas por principio".

${ }^{20}$ DwORKIN, Ronald, Los Derechos... (n. 8), p. 146. "En el positivismo jurídico encontramos una teoría de los casos difíciles. Cuando un determinado litigio no se puede subsumir claramente en una norma juridica, establecida previamente por alguna institución, el juez -de acuerdo con esta teoría- tiene discreción para decidir el caso en uno u otro sentido. Esta opinión supone, aparentemente, que una u otra de las partes tenía un derecho preexistente a ganar el proceso, pero tal idea no es más que una ficción. En realidad, el juez ha introducido nuevos derechos jurídicos que ha aplicado después, retroactivamente, al caso que tenía entre manos. En los dos últimos capítulos sostuve que esa teoría de adjudicación de competencias al juez; en este capítulo he de presentar y defender una teoría mejor. Mi argumento será que, aun cuando ninguna norma establecida resuelva el caso, es posible que una de las partes tenga derecho a ganarlo. No deja de ser deber del juez, incluso en los casos difíciles, descubrir cuáles son los derechos de las partes, en vez de inventar retroactivamente derechos nuevos".

${ }^{21}$ DwORKIN, Ronald, Los Derechos... (n. 8), pp. 146-147. "Quizás algún lector objete que si no existe, ni siquiera en principio, ningún procedimiento para demostrar qué derechos tiene las partes en los casos difíciles, de ello se sigue que no tienen ninguno. La objeción presupone una tesis discutible de filosofía general, a saber, que ninguna proposición puede ser verdadera a menos que se pueda demostrar que lo es, en principio".
} 
Este segundo contraargumento está viciado -como Dworkin admite- por el escaso -sino nulo- acuerdo que existe en relación al concepto de democracia ${ }^{22}$. Por esta razón, Dworkin postula un concepto particular de democracia;

"[D]efenderé una explicación que denomino concepción constitucional de la democracia, que no rechaza la premisa mayoritarista. Niega que sea un objeto definitorio de la democracia que las decisiones colectivas siempre o normalmente sean aquellas que una mayoría favorecería si estuviera totalmente informada y fuera racional. Mi explicación considera que el objetivo definitorio de la democracia es otro: que las decisiones colectivas sean tomadas por instituciones políticas cuya estructura, composición y prácticas traten a todos los miembros de la comunidad como individuos, con igual consideración y respeto. Esta concepción alternativa de la finalidad de la democracia en verdad requiere de la misma estructura de gobierno que la premisa mayoritarista. Requiere que las decisiones políticas del día a día sean tomadas por funcionarios elegidos en elecciones populares. Pero la concepción constitucional requiere estos procedimientos mayoritarios como resultado de su consideración por el estatus igual de los ciudadanos, y no por estar comprometida con el ideal de la regla de la mayoría"23-24.

El modelo de democracia de Dworkin, como sugiere la cita, rechaza que la legitimidad de las decisiones esté basada en el mayoritarismo como regla procedimental ${ }^{25}$. Al contrario, sugiere que el procedimiento de toma de decisiones mayoritarias respete la igual consideración de todos los ciudadanos en el resultado de ese proceso político. Ahora bien, el guardián de la igual consideración en el resultado de ese proceso legislativo, difícilmente -de acuerdo a Dworkin- puede ser el propio Poder Legislativo el que de esa manera se convertiría en juez de su propia causa. No resulta equitativo que estos derechos concebidos como cartas de triunfo contra las mayorías, pueden ser decididas -en su alcance y peso- por las mayorías ${ }^{26}$. No es cierto, señala Dworkin, que las decisiones sobre cuestiones morales y

22 DWORKIN, Ronald, "La lectura moral... (n. 5), pp. 155-117.

${ }^{23}$ DWORKIN, Ronald, “La lectura moral... (n. 5), p. 117.

${ }^{24}$ DWORKIN, Ronald, "La lectura moral... (n. 5), p. 107. "Creo que los principios establecidos en el Bill of Rights, tomados en conjunto, comprometen a Estados Unidos con los siguientes ideales políticos y jurídicos; el gobierno debe tratar a quienes están sujetos a su imperio como si tuvieran igual estatus moral y político; debe intentar, de buena fe, tratarlos a todos con igual consideración; y debe respetar todas las libertades individuales indispensables a tales fines, incluyendo pero no limitándose a las libertades más específicamente definidas en el documento, tales como la libertad de expresión o de religión".

${ }^{25}$ DwORKIN, Ronald, Los Derechos... (n. 8), p. 211. "La teoría constitucional sobre la cual se basa el gobierno de los Estados Unidos no es una simple teoría mayoritaria. La Constitución, y particularmente el Bill of Rights, está destinada a proteger a los ciudadanos, individualmente y en grupo, contra ciertas decisiones que podría querer tomar una mayoría de ciudadanos, aun cuando esa mayoría de ciudadanos actúe siguiendo lo que para ella es el interés general o común".

26 DWORKIN, Ronald, Los Derechos... (n. 8), p. 223. "Empezaré por el segundo argumento, el que afirma que el parlamento y otras instituciones democráticas tienen títulos especiales para tomar decisiones constitucionales, aparte de su capacidad para tomar mejores decisiones. Se podría decir que la naturaleza de tales títulos es obvia, porque siempre es más equitativo que un problema lo resuelva una mayoría que una minoría. Pero esta es una posición que, como con frecuencia se ha señalado, pasa por alto el hecho de que las decisiones referentes a derechos en contra de la mayoría no son problemas que equitativamente deban quedar librados a la mayoría. El constitucionalismo -la teoría de que a la mayoría hay que restringirla para proteger los 
políticas deben ser refrendadas solo por órganos políticamente responsables. Un argumento de ese estilo se basa únicamente en que eso es lo que dicta el concepto de democracia, y una fundamentación tan formalista pasa por alto que el concepto de democracia no es precisamente unívoco, y además tampoco es el concepto que se ha utilizado en los Estados Unidos de América ${ }^{27}$.

Si verdaderamente los derechos son cartas de triunfo frente al soberano, entonces ya no puede ser el soberano quien decide el sentido y alcance de estos diques constitucionales contra sí mismo, sino que ese papel queda radicado en jueces alejados de la contingencia de la vida política, y con habilidades especiales para interpretar las cláusulas constitucionales de acuerdo a determinados procedimientos. Mediante estos, los jueces deben interpretar las cláusulas constitucionales evitando en lo posible el activismo judicial, esto es, llenando el contenido de dichas cláusulas, actuando tal como si fuera un legislador.

El activismo judicial es -de acuerdo a Dworkin- un defecto propio del positivismo jurídico, que deja al juez fuera de los límites del lenguaje impuesto en el texto jurídico, libre para decidir el caso conforme si fuera un legislador proactivo. La lectura moral de la Constitución que propone Dworkin también está cerca de esta crítica, pero está -supuestamente- más lejos de ella que la discreción judicial en sentido fuerte del positivismo. Dicha lectura moral no viene a usurpar los privilegios del pueblo, por tal razón si bien los jueces deben interpretar la Constitución -o las cláusulas vagas de esta- tal como si se tratara de principios morales, no cualquier conclusión a la que el juez llegue puede ser correcta -si no no habría diferencia con la discreción judicial en sentido fuerte del positivismo-, sino que esta interpretación debe estar sujeta a ciertos estándares. En primer lugar, el juez debe respetar la integridad del texto constitucional, esto es, no debe llenar a priori el contenido de las garantías constitucionales incorporando su propia moralidad al texto constitucional. En segundo lugar, la conclusión a la que el juez llegue respecto de la aplicación del principio general al caso concreto debe tener coherencia con la Constitución como un todo y guardar coherencia al mismo tiempo con los antiguos lineamientos de otros jueces para otros casos, que pueda considerarse que poseen un particular peso gravitacional en la historia institucional de la judicatura ${ }^{28}$. En consecuencia, como la particular concepción del principio al que está arribando el juez, debe guardar consonancia con la historia institucional de la judicatura, el juez debe reconstruir dicha historia para cotejar cuáles son estas decisiones importantes que

\footnotetext{
derechos individuales- puede ser una teoría buena o mala, pero es la que han adoptado los Estados Unidos, y hacer que la mayoría sea un juez en su propia causa parece incongruente e injusto. Es decir que los principios de equidad, no hablar a favor del argumento de la democracia, sino en su contra".

27 DWORKIN, Ronald, Los Derechos... (n. 8), p. 222.

${ }^{28}$ DWORKIN, Ronald, "La lectura moral... (n. 5), p. 110. "La interpretación constitucional es disciplinada, según la lectura moral, por el requisito de integridad constitucional. Los jueces no pueden leer sus propias convicciones en la Constitución. No pueden leer las cláusulas morales abstractas como si se tratara de un juicio moral particular, sin importar cuánto les importa ese juicio, a menos que lo consideren consistente, al menos en principio, con el diseño estructural de la Constitución como un todo, y también con los lineamientos dominantes de antiguas interpretaciones de otros jueces. Deben mirarse a sí mismos como socios de otros funcionarios, del pasado y el futuro que, en conjunto, elaboran una moral constitucional coherente, y deben tener cuidado de ver que lo que ellos aporten se ajuste al resto. -En otro lugar, he dicho que los jueces son como autores que están creando conjuntamente una novela encadenada, en la cual cada uno escribe un capítulo que tiene sentido como parte de toda la historia en conjunto-".
} 
tienen la facultad - por su particular fuerza gravitacional- de llenar de contenido el principio que pretende aplicar al caso actual. El juez debe en todo caso discriminar entre aquellos fallos cuyo fundamento radica en principios generales del derecho de aquellos que se fundamentan en directrices políticas -que no tienen peso gravitacional alguno, y cuya utilización convertiría el juez en un activista político- ${ }^{29}$. Sin embargo, esta tarea resulta ser al menos titánica, por lo tanto, el juez que la emprenda debe tener una capacidad intelectual comparable a la fuerza física de un hércules ${ }^{30-31}$. A modo de ejemplo, no podría el juez sostener -al menos desde la Constitución de los Estados Unidos- que la igualdad de consideración y respeto implica que es deber constitucional del Estado brindar tratamiento heroico y experimental para todos aquellos cuyas vidas podrían ser salvadas ${ }^{32}$.

Así, de este modo, las objeciones democráticas a un juez políticamente activo en el positivismo de la discreción en sentido fuerte, sería salvado por este juez-filósofo, quien descubre el principio aplicable conforme a la aplicación de la Constitución como un todo coherente, fallando y juzgando a las partes conforme a un derecho en todo caso preexistente.

Sin embargo, para demostrar la veracidad de la opinión formulada en la introducción, requiere que niegue la posibilidad de una única respuesta al cual un juez -aun un hércules- pueda alcanzar sin antes leer su propia moralidad en las cláusulas abstractas de la Constitución, lo que de paso niega, que la democracia consista en que jueces alejados de la contingencia de la vida política interpreten la Constitución de forma avalorativa por encima de lo refrendado por la mayoría cuando alguna carta de triunfo de los ciudadanos ha sido dañada. Esto es así, pues política -además de provenir del latín polis- tiene su raíz en la palabra polemos, que quiere decir polémica, lo que sitúa al conflicto en el centro de la acción política $^{33}$. Ese conflicto, como veremos, se extiende a la interpretación de las cláusulas abstractas de la Constitución.

La política es esencialmente adversarial, y puede reflejarse en ella la relación amigo/ enemigo. Es innegable en la política la constitución de una identidad determinada en tor-

\footnotetext{
${ }^{29}$ DwóRKIN, Ronald, "La lectura moral... (n. 5), pp. 56-158. "La tesis requiere ser ampliada en tres direcciones. Se apoya, primero, en una distinción general entre derechos individuales y objetivos sociales, y esa distinción debe ser enunciada con más claridad que la que se deriva de menos ejemplos."... "Los argumentos de principio se proponen establecer un derecho individual; los argumentos políticos se proponen establecer un objetivo colectivo. Los principios son proposiciones que describen derechos; las políticas son proposiciones que describen objetivos".

${ }^{30}$ Lo curioso es que Dworkin niega que por esta situación los jueces que requieren su teoría sean filósofos reyes; ver DwORKIN, Ronald, "La lectura moral... (n. 5), p. 111. Pero sí acepta que sea al menos un juez filosofo. Ver DworkIN, Ronald, Los Derechos... (n. 8), p. 177.

${ }^{31}$ Ibid. "Por consiguiente, haríamos bien en considerar de qué manera, en los casos adecuados, un juez filósofo podría elaborar teorías sobre qué es lo que exigen la intención de la ley y los principios jurídicos. Nos encontraremos con que diseñaría tales teorías de la misma manera que un árbitro filósofo delinea el carácter de un juego. Para este propósito he inventado un abogado dotado de habilidad, erudición, paciencia y perspicacia sobrehumanas, a quien llamaré Hércules. Supongo que Hércules es juez de alguna jurisdicción importante de Estados Unidos. Supongo que acepta las principales normas constitutivas y regulativas no controvertidas del derecho en su jurisdicción. Es decir que acepta que las leyes tienen el poder general de crear y extinguir derechos, y que los jueces tienen el deber general de ajustarse a las decisiones anteriores de su tribunal o de tribunales superiores cuyas bases lógicas, como dicen los juristas, abarquen el caso que tienen entre manos".

32 Dworkin, Ronald, "La lectura moral... (n. 5), p. 111.

${ }^{33}$ ATRIA, Fernando. "Sobre la Soberanía y lo Político", en: Revista Derecho y Humanidades No 12, pp. 83-84. Santiago: Universidad de Chile, 2006.
} 
no a las cuestiones más relevantes de la comunidad, y obviamente, no es posible hablar de identidad, sino en un sentido estrictamente relacional, si se ha configurado una identidad es porque se ha establecido una diferencia, y ello implica otorgar a la política una naturaleza necesariamente antagónica ${ }^{34}$. Para cierta parte de la filosofía política, este antagonismo no es necesariamente resuelto en el plano de la racionalidad o la moralidad, de tal manera de que a través de ellas lleguemos a soluciones imparciales sobre lo que es justo.

Esta última idea es contraria a lo que se conoce como democracia deliberativa, concepto analizado entre otros por Carlos Santiago Nino. De acuerdo a este autor, las preferencias individuales de los ciudadanos pueden, a través de la deliberación pública, transformarse en concepciones imparciales sobre el bien público, de esta forma, las soluciones legislativas tienen una mayor pretensión de legitimidad por sobre aquella política basada en facciones o en la suma de preferencias individuales. De esta manera, la deliberación no es la "suma de reflexiones individuales que operan en forma aislada, sino que es un proceso colectivo en el cual la posición de cada participante se vuelve cada vez más focalizada como consecuencia de reaccionar frente a los argumentos de otros, La reflexión de cada uno se ve así enriquecida por la de los demás" 35 .

Similar concepción de la política tiene Habermas, quien identifica este potencial transformador de las concepciones prepolíticas, a un ideal estrictamente republicano. Primero para contrastar, identifica a la concepción liberal de la política como la lucha de posiciones que posibilitan el poder disponer de poder administrativo ${ }^{36}$. El mecanismo en el que se juega la posibilidad de poder disponer de poder administrativo es el voto, cuyo cantidad mide el consentimiento del elector con personas y programas. La elección a través del voto funciona de la misma manera que los oferentes y demandantes en el mercado ${ }^{37}$, en los que el ciudadano vota de acuerdo a sus preferencias individuales. Este modelo lo caracteriza Habermas como escéptico respecto del papel de la razón en el proceso político ${ }^{38}$, precisamente de la manera en Dworkin lo expone, quien duda que las decisiones políticas sean más correctas si se dejan a las mayorías que si se dejan a un tribunal. Por otro lado, de acuerdo al ideal republicano, la voluntad política no se estructura conforme a procesos de mercado, sino más bien orientados a procesos de entendimiento y deliberación. "Imagina la política como una

\footnotetext{
34 Ver MOUfFe, Chantal. "Democracia y Pluralismo Agonístico", en: Revista Derecho y Humanidades N 12, p. 20. Santiago: Universidad de Chile, 2006. "Emplearé la noción de exterior constitutivo para explicar mi argumento. Este término ha sido propuesto por Henry Staten para referirse a una serie de temas desarrollados por Jacques Derrida a través de nociones tales como suplemento, marca y differance. Su objetivo es el de subrayar el hecho de que la creación de una identidad supone el establecimiento de una diferencia, diferencia que es a menudo construida sobre la base de una jerarquía; por ejemplo, entre forma y materia, negro y blanco, hombre y mujer, etc. Una vez que hemos comprendido que toda identidad es relacional y que la afirmación de una diferencia -es decir, la percepción de otro que constituye su exterior-es una precondición para la existencia de cualquier identidad, podemos formular mejor la idea de Schmitt acerca de la posibilidad siempre presente de la relación amigo/enemigo; o para decirlo de otro modo, podemos comenzar a percibir de qué modo una relación social puede convertirse en el terreno de producción de un antagonismo".

${ }^{35}$ Nino, Carlos Santiago. La Constitución de la Democracia Deliberativa. Barcelona: Editorial Gedisa, año 1997, p. 210.

${ }^{36}$ HaberMaS, Jürgen. Facticidad y Validez. Madrid: Editorial Trotta, S.A. 1998, p. 346.

37 Ibid.

${ }^{38}$ HABERMAS, Jürgen, op. cit. (n. 36), p. 348.
} 
disputa acerca de cuestión de valor y no simplemente acerca de cuestiones de preferencia"39. Sin embargo, el republicanismo posee una sobrecarga ética que no otorga condiciones para que la deliberación pública tenga lugar de una manera deseable. Los momentos deliberativos son, en el ideal republicano, excepcionales. Son excepcionales porque el republicanismo supone una sociedad éticamente articulada en forma previa al discurso ${ }^{40}$. Ese ideal puede remontarse a Rousseau, quien no concibe al ciudadano montado en una especie de ágora ateniense, discutiendo, evaluando y contraargumentado concepciones acerca del bien público $^{41}$. Por esta razón, el discurso deliberativo debe desmontarse de la sobrecarga ética del republicanismo, y centrar su atención en las condiciones procedimentales necesarias para la deliberación, que permita que se impongan los mejores argumentos ${ }^{42}$.

A todo ello, en todo caso, Waldron previene en que si bien es posible dejar las diferencias acerca de la idea del bien público a la deliberación pública racional, de tal manera que las soluciones a que se arriben al final de la jornada satisfaga a todos los participantes, por tratarse de un consenso racional o una solución imparcial del conflicto primitivo, muchas veces nos encontraremos con que el discurso público racional en vez que acercar las posiciones las haya acentuado, y los ciudadanos tengan aún mayores razones para fundamentar su propia posición y negarse a llegar a un consenso racional sobre el conflicto primitivo. En ese caso, se procede a contar -en vez de cortar- las cabezas, y zanjar la duda a través del voto $^{43}$. En ese caso, volvemos a considerar la política como esencialmente adversarial, cuya solución a los antagonismos no puede ser dejada por regla general, a la moral y a la razón.

\section{EL PAPEL DEL DERECHO}

Sea que consideremos que las distintas concepciones acerca del bien público puede ser resuelta a través de la deliberación pública racional -Nino; Habermas-, o al contrario, son necesarios otros mecanismos de solución puesto que los antagonismos no pueden ser resueltos a través de la moral -Mouffe-, o que sí podemos someterlo a una deliberación publica racional pero asumiendo que las diferencias pueden acentuarse -Waldron-, una cosa sí es común; la existencia de una oposición. Esta oposición [ética o simplemente existencial] debe ser resuelta a través de mecanismos que sean inclusivos en términos de procedimiento, esto es, normas refrendadas por el pueblo a través de los parlamentos. Al contrario, el concepto de democracia de Dworkin es, según la caracterización realizada, una democracia

\footnotetext{
${ }^{39}$ HABERMAS, Jürgen, op. cit. (n. 36), p. 347.

${ }^{40}$ HABERMAS, Jürgen, op. cit. (n. 36), p. 352.

41 Uno de los pasajes en donde esto se vislumbra en ROUSSEAU, J.J. El Contrato Social. Madrid: Editorial Alba, 1998, p. 43. "La primera y más importante consecuencia de los principios formulados anteriormente es que solo la voluntad general puede dirigir las fuerzas del Estado con arreglo a la finalidad de su institución, que es el bien común, pues si la oposición de intereses particulares hizo necesario el establecimiento de las sociedades, es también la coincidencia de estos intereses la que la hizo posible. Lo que hay de común entre estos intereses es lo que forma el vínculo social, y si no existiera algún punto de coincidencia entre todos los intereses sería imposible la existencia de cualquier sociedad. Es únicamente sobre la base de este interés común como debe gobernarse la sociedad".

${ }^{42}$ Habermas, Jürgen, op. cit. (n. 36), p. 353.

43 WaLdRON, Jeremy. "Deliberación, desacuerdo y votación”, en: KOH, Harold Hongju y Stye, Ronald C. (comp.). Democracia Deliberativa y Derechos Humanos. Editorial Gedisa, 2004.
} 
de tipo elitista, que presume que las mejores decisiones democráticas son aquellas tomadas por un grupo selecto de ciudadanos, que por su buen juicio, sabiduría e imparcialidad, sabe mejor que el pueblo lo que es mejor para el pueblo. Este tipo de democracia presume que la comunidad política no ejerce su libertad en sentido estricto, al darse las políticas que refrendan a través de actos legislativos, más bien presume que dichas políticas son el producto de la azarosa acumulación de intereses individuales. Por lo tanto, ante la sanción a una ley por antidemocrática, la libertad de nadie ha sido ofendida.

Si llevamos esto al problema del control jurisdiccional de constitucionalidad, al interpretar un derecho constitucional a título de principio informador de la ley ordinaria, al juez no le queda alternativa que ser un activista político. Esto es así, en palabras del filósofo del derecho chileno Atria, pues una teoría del control constitucional no distingue entre conceptos y concepciones ${ }^{44}$, las cláusulas vagas de la Constitución son formulaciones abstractas incontrovertibles, pero que por tal razón no tienen la fisonomía propia de una norma jurídica, por lo tanto, no son ejecutables por el juez. A eso remite la idea de un concepto, el cual debe ser llenado de contenido con una concepción particular de lo que ese concepto debe querer decir. Por ejemplo, un liberal y un socialista están de acuerdo como premisa constitucional fundamental la igualdad de consideración. Ambos están de acuerdo que la igualdad como concepto es parte constitutiva del orden social, pero al momento de definir el contenido concreto del abstracto concepto de igualdad, muy por el contrario, estarán en desacuerdo. En consecuencia, cuando el juez juzga sobre qué concepción particular del concepto de igualdad es aquel que la Constitución defiende, al momento de definir si la ley se ajusta al contenido de la Constitución, tendrá que decidir o como liberal o como socialista, y declarar constitucional o inconstitucional la ley según corresponda ${ }^{45}$. Desde luego, la objeción salta a la vista, el papel del legislador se transfiere subrepticiamente desde un órgano políticamente responsable y popularmente elegido a uno sin responsabilidad política ni legitimidad democrática. De acuerdo a esta teoría, el control abstracto de constitucionalidad nos lleva a una virtual tiranía judicial.

De acuerdo a lo señalado más arriba -según Dworkin-, el juez no debe tener la posibilidad de decidir o como socialista o como liberal, sino que debe velar por descubrir cuál de esas posibilidades tiene coherencia con la Constitución como un todo, y por otro lado, el juez debe hacer primar los derechos individuales por sobre objetivos colectivos. Sin embargo, la respuesta a esa posible contraargumentación, es que el juez sigue ejerciendo un control inadecuado de constitucionalidad. Supongamos que una interpretación de la igualdad como "carta de triunfo" frente al Estado no permita sino una lectura liberal de dicho concepto, ¿se sigue necesariamente de dicha circunstancia que el juez debe rechazar la ley que le otorgue al concepto constitucional de igualdad un contenido distinto al liberal?, si la respuesta es sí, significa que el soberano está imposibilitado de otorgar contenido a las cláusulas abstractas de la Constitución.

\footnotetext{
${ }^{44}$ ATRIA, Fernando. "El derecho y la contingencia de lo político" [disponible en: http://descargas.cervantesvirtual.com/servlet/ SirveObras/doxa ], p. 331.

45 Ibid.
} 
Los derechos como cartas de triunfo son asimilables - no exactamente lo mismo, pero asimilables- a la idea de Ackerman sobre la justificación del control de constitucionalidad. Ackerman en su modelo democracia dualista distingue entre dos momentos constitucionales. Un primer momento constitucional de agitación política -momento corto-, en donde los principios políticos que regirán las futuras generaciones son acordados -deliberación mediante- por un número extraordinario de ciudadanos. Luego un segundo momento constitucional de normalidad política -momento largo-, los ciudadanos ejercerán su libertad política a través de los actos del Legislativo, respetando los acuerdos sobre derechos de aquel primer momento constitucional ${ }^{46}$. De esta manera, los derechos concebidos en el primer momento constitucional, atan a las mayorías ocasionales en los momentos de normalidad ${ }^{47}$.

Que esta idea acerca de los derechos como cartas de triunfo en tanto ataduras al firme mástil del Tribunal Constitucional, que aleja al Parlamento de un ocasional, enardecido y nunca relevante canto de sirenas ${ }^{48}$, sea una respuesta definitiva al problema del control de constitucionalidad, está lejos de ser verdadero. Saltan a la vista varias críticas; primero, nada asegura que en aquel primer momento constitucional el pueblo se manifieste, bien puede ser el acuerdo de un grupo de elite conformado a través de una comisión constituyente. En segundo lugar, en los momentos de normalidad política se puede llegar a acuerdos tan trascendentales y que aúne las voluntades de un número extraordinario de ciudadanos que, siendo legítimo, no prospere por no tener consonancia con lo acordado por dudosas mayorías políticas decenas o cientos de años atrás. En tercer lugar, los jueces constitucionales no se limitarán a dar lectura a la Constitución, muchas veces deberán llenar el contenido de las cláusulas vagas de esta y convertirse de esa manera en activistas políticos ${ }^{49}$. En consecuencia, tanto la lectura moral de Dworkin como la democracia dualista de Ackerman, no dan respuesta suficiente a la justificación del control jurisdiccional de constitucionalidad, y no son deferentes, en caso alguno, con la soberanía popular.

La misma objeción se extiende a la aplicación directa de la Constitución por parte del juez ordinario, al hacer directamente aplicables los principios constitucionales, los cuales respecto de su contenido se entiende que existe una oposición esencial; el juez deberá resolver esa oposición. Si consideramos que esa oposición no puede ser resuelta a través de la razón, entonces ni siquiera diez Hércules de Dworkin podrán resolver la problemática de una manera imparcial. Por otro lado si consideramos que si puede ser resuelta a través de la

\footnotetext{
46 Ver esta caracterización en RUIz SCHNEIDER, Carlos. "Democracia y Liberalismo en Ronald Dworkin", en: Revista Derecho y Humanidades $\mathrm{N}^{\circ}$ 14, p. 26. Santiago: Universidad de Chile, 2008.

47 ACKERMAN, Bruce. La nueva división de poderes. México: Fondo de Cultura Económica, 2007, p. 53. "Esta división de poderes inicial desemboca en otro proceso. Requeriremos un tribunal constitucional para convertir los principios promulgados por el pueblo en realidades operacionales. Sin la institución de revisión judicial, la mayoría parlamentaria dominante tendría entonces enormes incentivos para ignorar actos anteriores de soberanía popular cuando le fuera conveniente. Este resultado solo generará cinismo acerca de la posibilidad misma de que el pueblo sea capaz de dar órdenes de movilización a sus representantes gubernamentales y esperar que ellos les obedezcan. Únicamente un tribunal constitucional poderoso puede cumplir con esta función".

${ }^{48}$ Metáfora de ElSTER, J. Citado por ATRIA, Fernando. "El derecho y' la contingencia de lo político", en: Revista del Centro de Estudios Públicos, 2000, p. 319.

${ }^{49}$ GARGARELLA, Roberto. La justicia frente al gobierno, sobre el carácter contramayoritario del poder judicial. Barcelona: Editorial Ariel S.A., 1996, pp. 54-57.
} 
razón o de la moral, el problema persiste, pues la solución debe encontrarse en la deliberación pública que sea inclusiva en términos de procedimiento -Poder Legislativo-, que es la única garantía de que el resultado de ese proceso de toma de decisiones públicas, sea el más justo.

Por esa razón es que el sistema jurídico es un sistema compuesto esencialmente de reglas, que es el producto final de la deliberación pública que tiene por objeto dotar de contenido preciso a las cláusulas abstractas de la Constitución ${ }^{50}$. Ese contenido concreto se especifica a través de reglas, respecto de los cuales los jueces son aplicadores. Cabe notar, sin embargo, que no se trata que los jueces sean la boca muerta que pronuncia las palabras de la ley, a la manera de Montesquieu. Esto es así, pues la ley está hecha para un género de casos que quedan regidos por la norma; el juez, que debe ser independiente para atender el caso en sus propios términos, puede eventualmente considerar que el caso sometido a su conocimiento no pertenece al género para el cual la norma se ha creado, en cuyo caso, podría derrotar la regla. Por esta razón los jueces no pueden ser computadoras, y no son, en ningún caso, la boca muerta que pronuncia la palabras de la ley. Naturalmente, existe una discusión bastante intensa relativa a la derrotabilidad de las reglas, y no es objeto de este trabajo profundizar en esto ahora ${ }^{51-52}$. Sea que pensemos que es posible derrotar la regla o no, la tesis

50 ATRIA, Fernando. "La ironía del positivismo jurídico" [disponible en: http://www.cervantesvirtual.com/servlet/SirveObr as/09259512077961540032268/028045.pdf] "Un nuevo fantasma recorre Europa. El fantasma del neo-constitucionalismo. Los poderes de la cultura jurídica europea han entrado una santa alianza no para exorcizarlo sino para defenderlo e incluso exportarlo: jueces y abogados, académicos y profesores de derecho, intelectuales italianos y filósofos alemanes. El primer fantasma prometía emancipación pero finalmente llevó al totalitarismo; el segundo promete igualdad y libertad para todos pero pone en peligro nuestra capacidad para autogobernarnos democráticamente y el estado de Derecho como gobierno de las leyes, y no de hombres y mujeres", p. 118.

51 Ver por ejemplo, ATRIA, Fernando. "Las Circunstancias de la Derrotabilidad", en: Revista de Ciencias Sociales, N 45 . Valparaíso: Universidad de Valparaíso, 2000. "Las reglas jurídicas típicamente operan conectando ciertos hechos -operativos- una consecuencia jurídica, de modo que cuando los hechos operativos ocurren en el mundo, la consecuencia jurídica es, de acuerdo al derecho, debida. - Lo peculiar del derecho probablemente una de las razones que llevó a Celso a sostener que el derecho era ars boni et aequi, el arte de lo bueno y de lo justo- es que esto no es siempre el caso: la ocurrencia de los hechos operativos de una regla jurídica no necesariamente implica que, conforme a derecho, la consecuencia fijada por esa misma regla es debida: las reglas jurídicas son derrotables. Se dice de una norma que es derrotable cuando la exigencia que ella contiene debe ser cumplida en la generalidad de los casos, aunque pueda ser derrotada en otros. La derrotabilidad es característica de (algunas) normas generales", p. 437.

52 Por otro lado, ver GUASTINI, R. "Variaciones sobre temas de Carlos Alchourrón y Eugenio Buligyn, derrotabilidad, lagunas axiológicas e interpretación", en: Análisis Filosbfico XXVI No 2, pp. 277-293, noviembre 2006. "Los conceptos de derrotabilidad y de laguna axiológica son nuevos (o relativamente nuevos) en el lenguaje de la teoría del derecho, pero ambos son, a menudo, el resultado de una forma de interpretación bien conocida: la interpretación restrictiva, o sea aquella interpretación que reduce el alcance de una norma. Por otra parte, el concepto de interpretación restrictiva es, evidentemente, un concepto de relación: ¿"restrictiva" con respecto a qué? Para afirmar que una interpretación es restrictiva hace falta presuponer una interpretación distinta: normalmente, una interpretación literal. Nótese, sin embargo, que incluso la interpretación literal es una interpretación, tal vez menos discutible, pero -en tanto interpretación no más "objetiva" o "neutral" que otras interpretaciones posibles. La interpretación restrictiva, como cualquier interpretación no literal, supone, explícita o tácitamente, el argumento -retórico- de la ratio legis, o sea de la intención -a menudo contrafáctica- de la autoridad normativa. Más precisamente, quien rechaza la interpretación literal supone: primero, que existe una discrepancia entre lo que la autoridad normativa ha dicho y lo que quería decir -o hacer-; segundo, que la intención tiene que prevalecer sobre el texto. Esta última suposición, evidentemente, no es otra cosa que una ideología política. Por otra parte, los enunciados sobre la intención de las autoridades normativas no pueden seriamente ser considerados como enunciados empíricos: no existe acceso a la "mente" de un legislador, sobre todo si es un órgano colegiado", pp. 286-287. 
principal queda indemne; las cláusulas abstractas de la Constitución requieren de concreción legislativa.

\section{IGUALDAD ANTE LA LEY Y PREDECIBILIDAD}

Con el análisis realizado en los dos acápites anteriores, es más fácil un acercamiento crítico a esta afirmación realizada por el académico chileno Humberto Nogueira Alcalá:

"Por otra parte, el desarrollo de una jurisprudencia constitucional especializada que tiene como finalidad la defensa del orden constitucional democrático, con competencia para determinar el sentido y alcance de los enunciados normativos constitucionales, y determinar a través de sus sentencias, toda normativa y toda actuación de los. poderes constituidos contrarios a la Carta Fundamental, obliga a los jueves ordinarios a tener en consideración y ajustarse en principio, a las líneas jurisprudenciales emanadas de sus fallos (la ratio decidendi)" 53 .

De acuerdo a estas palabras, el Estado Constitucional Democrático exige la existencia de una jurisdicción constitucional especializada, que proteja el orden constitucional estatuido, y establezca la obligatoriedad de la ratio decidendi de la jurisprudencia emanada de estos tribunales. La -supuesta- vinculación del juez a considerar esta línea de argumentación constante, deriva de dos principios fundamentales; el principio de la igualdad ante al ley, el derecho fundamental que ante supuestos esencialmente semejantes, se aplique e interprete sin diferencia a los distintos sujetos ${ }^{54}$. Y la seguridad o certidumbre jurídicas, basado en la razonable previsibilidad de la actuación del juez.

En cuanto a la seguridad jurídica, Garrido Gómez identifica cuatro manifestaciones; a) certeza en la orientación; b) certeza en la existencia; c) la predecibilidad jurídica; d) la firmeza del Derecho ${ }^{55}$. En este sentido, no basta la congnoscibilidad de la norma jurídica, sino que también la predecibilidad de su aplicación concreta, lo que redunda en la exigencia

\footnotetext{
53 Nogueira Alcalá, Humberto, op. cit. (n. 2), p. 8.

${ }^{54}$ Ruiz-TAGLE, Pablo. "Análisis comparado de la función judicial", en: Derecho, Justicia y Libertad. Distribuciones Fontamara, México, 2002.

55 GARrido GómEZ, María Isabel, op. cit. (n. 2), p. 60. "En relación a la certeza de orientación y a la certeza de existencia, la seguridad del Derecho es, en primer lugar, certeza o certidumbre jurídica. Para Geiger, sería la circunstancia de que se conozca lo que está en el Ordenamiento, el saber acerca de las normas jurídicas o la cognoscibilidad de su contenido libre de dudas, lo cual permite a los ciudadanos conocer lo que está prohibido, impuesto o permitido, y poseer un conocimiento nítido de cuándo y cómo intervendrá el Estado en sus vidas. Esta certeza representa una necesidad de todo individuo que se rige en sus actos de conformidad con esas normas, una defensa frente a la arbitrariedad, un medio para evitar los conflictos jurídicos, así como una exigencia intrínseca del funcionamiento correcto de todo sistema. Sin embargo, no hay duda de que la certeza del Derecho ha sido y sigue siendo valorada por la seguridad de orientación que dispensa a los sujetos de Derecho a la hora de actuar, de proyectar y decidir poner en marcha un curso de acción. La anterior es una certeza que emana del conocimiento del contenido de las normas jurídicas que podría llamarse certeza de orientación y que debe ser distinguida de la certeza de existencia. Aspecto que depende de la conciencia de su existencia y vigencia, no de un acceso a los contenidos de la regulación jurídica. Son, por consiguiente, dos aspectos separables, si bien la certeza de orientación no es posible sin una previa certeza de existencia de la norma, no implicando la última, necesariamente, el conocimiento del contenido. Mientras que la primera depende de las cualidades del lenguaje jurídico que hacen comprensible el significado de la precisión, claridad, publicidad, etc.; la segunda
} 
de una orientación regular de los tribunales en la interpretación de las normas jurídicas, las que, en virtud de un mandato de predecibilidad e igualdad ante la ley, trate los casos semejantes en forma semejante.

Han surgido voces que, con el objeto de resguardar la igualdad ante la ley y la seguridad jurídica, ante la explosión de derechos como consecuencia de la doctrina de la aplicación directa de la Constitución, pretenden darle competencia al Tribunal Constitucional para que unifique doctrina sobre derechos fundamentales. Es el caso de Bordalí Salamanca. En este sentido, habiendo el Tribunal Constitucional sentado doctrina -jurisprudencia- sobre una materia determinada relativa a los derechos fundamentales, pueda anular sentencias contrarias dictadas por la Corte Suprema sobre la misma materia ${ }^{56}$. No obstante ello, no puede en caso alguno ser obligatorio para la Corte Suprema ni para los jueces inferiores - a menos que posea un determinado nivel de autoritas- pero pueden en todo caso ser dichos fallos anulados por la doctrina sobre derechos fundamentales previamente establecida por el Tribunal Constitucional. La discusión en el caso laboral es relevante, con la creación del nuevo procedimiento de tutela de derechos fundamentales que ratifica la aplicación directa de la Constitución, doctrina que se ha anclado en nuestro sistema jurídico con garras de felino.

La doctrina de la aplicación directa deviene con el cambio de paradigma del Estado de Derecho. Ha transitado desde una concepción del Estado de Derecho Tradicional, en que la ley determinaba el contenido de los derechos fundamentales a un Estado Constitucional Democrático, en donde el contenido de la ley se juzga de acuerdo a los parámetros otorgados por los derechos fundamentales contenidos en la Constitución ${ }^{57}$.

Este modelo de aplicación directa de la Constitución y obligatoriedad del precedente constitucional, nos acerca de manera gravitante al sistema anglosajón. En dicho modelo, lo que constituye el precedente obligatorio de las sentencias no es ni por mucho el cuerpo entero de las sentencias, sino solamente la ratio decidendi o holding, que puede definirse como

\footnotetext{
demanda la concurrencia de todos los indicios que permiten estimar que una norma posee existencia jurídica -publicación, ausencia de antinomias, jerarquía de fuentes-.

Por otro lado, en la certeza de contenido y de existencia descansa lo que clásicamente ha sido y continúa siendo un concepto restringido de seguridad jurídica, propiamente el de la predecibilidad del Derecho. La certeza de conocimiento permite a los ciudadanos conocer, con claridad y de antemano, lo que está prohibido y permitido y, en función de ese conocimiento, organizar su conducta presente y programar expectativas para su actuación jurídica futura bajo pautas razonables de predecibilidad. Al hacer esta aportación, el Derecho crea seguridad y confianza en la vida de cualquier organización social.

Concluyentemente, la certeza jurídica incluiría la firmeza del Derecho vigente. Además del contenido de las normas, integra la ausencia de dudas acerca de la plena vigencia de ciertas decisiones, las cuales no pueden ser muchas veces solo expresión de la razón, sino también una decisión, en principio definitiva o con pretensión de serlo, de aspiraciones o conflictos. Desde este punto de vista, Coing postula que la seguridad jurídica supone que los derechos, las posiciones de poder y de posesión, una vez. fundadas, tienen que subsistir sin que nadie las discuta o perturbe, y que las decisiones jurídicas, una vez formuladas, deben ser mantenidas. Ello posibilita que se pueda confiar en el Derecho como una magnitud fija, sustraída a toda transformación caprichosa, en función de la que el hombre puede ordenar su vida y ponerla bajo su protección".

${ }^{56}$ BORdali SalamanCA, Andrés. "La unidad en la interpretación jurisdiccional de los derechos fundamentales: una tarea pendiente en el derecho chileno", en: Revista Chilena de Derecho, vol. 43, N³, p. 517. Santiago: Pontificia Universidad Católica de Chile, 2007.

57 NOGUEIRA ALCALA, Humberto, op. cit. (n. 52), p. 7.
} 
las proposiciones juridicas enunciadas por el juez que son necesarias para la decisión adoptada ${ }^{58}$. Sin embargo, con la introducción de la práctica del overruling, ya no se concede a las sentencias que constituyen precedente un carácter absolutamente permanente, sino se permite que se modifiquen cuando la aplicación al caso actual ya no parece adecuada, y por razones de justicia y equidad deba el juez necesariamente cambiar el precedente. Se ha señalado que mediante este procedimiento se le quita el carácter efectivamente obligatorio al precedente judicial, pero se replica que la práctica del overruling no quita carácter obligatorio alguno al precedente judicial, sino que confirma su validez, pues mediante el cambio del precedente, se exige del juez un acto derogatorio expreso del precedente que viene a desechar, y no una simple fundamentación de fallar como falla en el caso actual -sino las razones de fallar como falla en el caso actual y una explicación profunda de por qué la utilización del precedente no era satisfactorio para el caso actual-.

Precisamente en nuestro Derecho del Trabajo, con la recepción legal de la doctrina de la aplicación directa de la Constitución, y su aparato conceptual esencialmente vago y cuya aplicación es irremediablemente controvertida, y un recurso que unifique jurisprudencia y que su fallo se pretenda obligatorio para géneros de casos futuros, dejamos las puertas abiertas para recepcionar el sistema del common law, y abandonar poco a poco el Estado de Derecho Tradicional en donde el juez aplica la ley, que es la única manera de especificar el contenido de la Constitución. Precisamente, la aplicación directa de esta provoca incertidumbre en la solución del caso controvertido, y la consecuente desigualdad en la aplicación de la ley. Otorgar efecto erga omnes a un recurso que unifique doctrina sobre derechos fundamentales, puede solucionar el problema, pero a costa de construir una cultura jurídica que identifica en un cuerpo de elite -Corte Suprema o Tribunal Constitucional-, la legitimidad de disponer el contenido de los derechos fundamentales, sin contar con una posición epistemológica superior a la de cualquier ciudadano para determinar dicho contenido. El problema aquí, como supongo ha quedado claro, ha sido desde un principio la aplicación directa de la Constitución.

\section{INDEPENDENCIA DEL JUEZ}

De acuerdo a Atria, el Poder Ejecutivo tiene una finalidad, que es la felicidad pública, para esos efectos el pueblo ha mandatado a una Presidente de la República -artículo 24 de la Constitución Política de la República, el gobierno y la administración del Estado corresponden al Presidente de la República-y los funcionarios públicos son respecto de él, sus dependientes. Los funcionarios públicos actúan como mandatarios o comisarios del Presidente de la República, actúan por cuenta y riesgo del mandante (P. de la R.). Esta modalidad organizacional no es propia de la judicatura. En primer lugar la judicatura no tiene una finalidad, sino una función, caracterizada como la función de "dar a cada cual lo suyo". Esta función no le corresponde a la Corte Suprema en particular, sino a los tribunales de la república en general -artículo 76 de la CPR: "La facultad de conocer de las causas civiles y criminales,

${ }^{58}$ LEGARRE, Santiago y RIVERA, Julio César, op. cit. (n. 3), p. 121. 
de resolverlas y hacer ejecutar lo juzgado, pertenece exclusivamente a los tribunales establecidos por la ley" ${ }^{59}$. En consecuencia, como la administración de justicia no está radicada en la Corte Suprema, sino en los Tribunales de la República, difícilmente podría existir una relación comisạrial entre el tribunal superior y los jueces inferiores, que atente contra la debida independencia interna del Poder Judicial.

Esta distinción no es nueva, ya Montesquieu había señalado que el poder de juzgar no debía estar en manos de un senado permanente, con el objeto de que se hiciera invisible y nulo y no adquiriera caracteres corporativistas ${ }^{60}$. Esta pretensión tiene directa relación con la independencia del juez para juzgar y "dar a cada cual lo suyo" en el caso concreto, pues a mayor autonomía del Poder Judicial menor es la independencia del juez con competencia para conocer el caso. Esto es así, porque una mayor autonomía demanda la profundización de las relaciones jerárquicas entre los jueces, aumentando los poderes direccionales de la Corte Suprema ${ }^{61}$.

Agustín Squella distingue una independencia externa y una independencia interna de los jueces. La independencia externa corresponde a la independencia de la judicatura de otros poderes públicos -Administración del Estado y Parlamentos-. La independencia interna, por su parte, dice relación con la independencia de cada juez con respecto a sus pares o sus superiores jerárquicos. He aquí la acepción del término independencia que nos parece relevante para efectos de analizar la función de las decisiones de la Corte Suprema en la orientación general de las decisiones de los jueces de la misma Corte o de inferior jerarquía. Para ello, permítaseme en esta parte una larga cita del profesor Squella respecto de la independencia interna del Poder Judicial;

"Se lesiona también la independencia interna de cada juez cada vez que los superiores jerárquicos, en particular la Corte Suprema, sin necesidad de inmiscuirse en un caso determinado que lleva un juez inferior, pretenden establecer criterio vinculantes para estos y válidos para géneros de casos acerca de cuál es el derecho aplicable y cómo debe ser este invariablemente interpretado y aplicado por los jueces cada vez que se produzca un caso previsto o cubierto por ese derecho" 62 .

\footnotetext{
${ }^{59}$ ATRIA, Fernando. "La improbabilidad de la jurisdicción", en: COUso, Javier y ATRIA, Fernando. La Judicatura como organización. Santiago: Instituto de Estudios Judiciales, 2005. [disponible en http://www.expansiva.cl/media/publicaciones/libros/ $\mathrm{pdf} / 5 . \mathrm{pdf}]$

60 Ver esta discusión en CORREA G., Rodrigo. "El gobierno judicial ante la Constitución”, en: Revista de Estudios de la Justicia $\mathrm{N}^{\circ}$ 6. Santiago: Centro de Estudios de la Justicia, Universidad de Chile, 2005. "Ciertamente esta idea- de Montesquieu también resulta impracticable. Pero no por ello es menos sorprendente que el gran teórico de los tres poderes del Estado haya pensado que si bien existe el poder de juzgar, el poder judicial, en cuanto órgano del Estado, es incompatible con la libertad republicana. Las demandas de autonomía del poder judicial, autonomía que sería administrada por la Corte Suprema de Justicia, encuentran a Montesquieu a su más férreo enemigo. No tienen, por otra parte, ningún amigo de su talla".

61 Ibid.

${ }^{62}$ SQUeLLA, Agustín. "Independencia interna del Poder Judicial: ante quiénes, en qué y para qué tenemos Jueces Independientes", en: COUSO, Javier y ATRIA, Fernando. La Judicatura como organización. Santiago:' Instituto de Estudios Judiciales, 2005, p. 19.
} 
La independencia tiene por objeto asegurar que el juez no esté sometido a presiones externas para decidir el caso sometido a su conocimiento, el cual siempre debe conocer en sus propios términos. Presiones del Poder Ejecutivo ante un caso determinado o la amenaza de la utilización de medidas de coacción por parte de jueces superiores, amenazan de manera gravitante la capacidad del juez para atender el caso en sus propios términos, quien no estará intelectualmente concentrado en determinar si el caso actualmente puesto a su conocimiento es del género de casos propuesto por la norma, o tiene características particulares especialmente relevantes que ameriten apartarse de la norma -ver problema de la derrotabilidad-.. Naturalmente, la independencia del juez proscribiría también la pretensión de establecer criterios vinculantes para jueces inferiores, como nos dice Squella, con algún mecanismo como el del precedente, proscripción que tiene por objeto dejar la administración de justicia en manos del Poder Judicial en general, y no en la Corte Suprema en particular.

\section{CONCLUSIONES}

De acuerdo a Rawls, la Corte Suprema de Justicia es un ejemplo de deliberación pública ${ }^{63}$. Para Chantal Mouffe, esta idea vislumbra lo poco que le queda a la política para determinar por sí misma qué es lo correcto para la comunidad ${ }^{64}$. Para los filósofos del derecho liberales, esta idea no es arbitraria, no se supone que lo que un parlamento determine es per se más justo que lo que determine un tribunal, el cual estaría más capacitado para determinar lo que es bueno y lo que es justo para dicha comunidad. No es extraño encontrar entre los ciudadanos norteamericanos, uno relativamente culto, que encontrará justificación para el aborto o la autodeterminación sexual de la mujer, no en un razonamiento moral con pretensiones de universalidad que fuera propio o de algún grupo respecto del cual comparte una identidad política, sino encuentra justificación en que la Corte Suprema de Justicia, en el caso Roe vs. Wade, dijo que la mujer podía abortar, como manifestación de su derecho a la autodeterminación sexual.

Estos casos poseen un peso gravitacional -para ocupar el aparato conceptual de Dworkin-, que los convierte en un precedente obligatorio para casos futuros, y puede vincular a los jueces cuando deban practicar lo que llaman la lectura moral de la Constitución. Esto constituye uno de los argumentos que ofrece Dworkin para demostrar que la lectura moral de la Constitución no es absolutamente arbitraria o subjeriva, sino que el juez usa una discreción en sentido débil, esto es, tiene una genuina discreción pero dentro de un marco preestablecido otorgado por la historia institucional de la judicatura que se manifiesta a través de los fallos que poseen un peso gravitacional determinado. De esa manera, evitamos que el juez lea su propia moralidad en la Constitución.

Claramente, eso -quizás- resuelva el problema de la arbitrariedad del juez que está vinculado por el precedente, pero ¿̇hemos de pensar que es obligatorio para los ciudadanos respetar la autodeterminación sexual de la mujer porque la Corte Suprema así lo dijo?, o al

63 Pensando particularmente en la Corte Suprema de Justicia de Estados Unidos.

${ }^{64}$ MOUfFE, Chantal, op. cit. (n. 34), p. 19. 
revés - para que el lector no crea que estoy dando una opinión política respecto del problema-, ¿hemos de aceptar los ciudadanos chilenos, que la mujer no tiene autodeterminación sexual en el plano del aborto, estando este proscrito, porque el Tribunal Constitucional así lo dijo? ¿Acaso podría un Hércules, o un juez con gran experiencia y méritos académicos, fallar de una manera imparcial, constituyendo de esa manera la moralidad pública y diciéndole al ciudadano que eso es lo que debe querer al ejercer su libertad?

Se ha sostenido que la Constitución Política de la República contiene un modelo de sociedad, y ese modelo de sociedad posee un guardián que ejerce un control de constitucionalidad sobre las leyes; dejando el modelo intacto ${ }^{65}$. Ese es uno de los principales problemas del -neo-constitucionalismo actual, que reniega de lo político y lo reduce a los momentos fundacionales. En esos momentos fundacionales se determina qué es lo que se deja a la política, y qué es aquello que constituye un derecho de defensa en contra del Estado-que atan a las mayorías ocasionales-. El problema con estos derechos de defensa, es que están amparados en fórmulas tan abstractas como igualdad y libertad, y ello unido a la creencia de que su aplicación al caso concreto puede ser descubierta objetivamente por grupos de jueces, deja al autogobierno democrático como premisa política en un pésimo esçenario. Ello es así pues no puede darse las normas que ellos estiman conveniente, porque un grupo de jueces cree que dicha norma no tiene coherencia con los derechos de defensa contra el Estado. Esos razonamientos judiciales, amparados en clave jurídica, no son sino un ejercicio político contramayoritario.

Mucho más coherente parece reconocer la oposición esencial que existe para interpretar de una u orra forma las cláusulas abstractas de la Constitución, puesto que oposición esencial existe en la política, de la manera en que lo analizamos cuando citamos a Mouffe, Habermas, Nino y Waldron, y la Constitución como carta política no queda fuera de ese conflicto. Por esa razón, como notamos más arriba, es que el sistema jurídico es un sistema compuesto esencialmente por reglas. Las reglas son las que otorgan definitividad a los dilemas éticos que se resuelven en la deliberación pública. Sin embargo, cabe no confundir definitividad con infalibilidad. Evidentemente la idea a través de la deliberación inclusiva en términos de procedimiento -requisito que no cumple la deliberación elitista de la Corte Suprema- es llegar a la única respuesta correcta - para usar el lenguaje de Dworkin, pero esta vez en el plano legislativo-. El objeto es que la solución final a la que se llegue sea moralmente incuestionable, pero no ocurre siempre; y si partimos de la base que estos conflictos no pueden solucionarse a través de la razón o de la moral, entonces siempre será una solución final absolutamente cuestionable para la minoría. Por esa razón, parece correcto hablar de definitividad, porque la norma adquiere en todo caso validez jurídica, pero no necesariamente infalibilidad ética ${ }^{66}$.

\footnotetext{
${ }^{65}$ Ver por ejemplo, BUSH VENTUR, Tania. "Aproximaciones al fundamento de la jurisdiccionalidad del control jurisdiccional", en: Revista Derecho y Humanidades $\mathrm{N}^{\circ} 12$, p. 277. Santiago: Universidad de Chile, 2006. "La propia existencia de la Constitución como norma jurídica fundamental justifica y exige el control de constitucionalidad de normas y actos, puesto que el compromiso del pueblo con el modelo de sociedad que anhela se ha elevado a categoría de derecho".

${ }^{66}$ Distinción hecha por ATRIA, Fernando. "La ironía (n. 50), p. 90.
} 
En consecuencia, si se quiere proteger la igualdad, la libertad, la honra o la dignidad de los trabajadores en el seno de la relación laboral, no basta con decir "aplíquese directamente la igualdad, la libertad, la honra o la dignidad en el seno de la relación laboral". No obstante, el neoconstitucionalismo avanza precisamente en esa dirección, y ve la ley como un conjunto de razones contribuyentes pero no necesariamente suficientes para solucionar el caso concreto. Como contribuyentes que son, siempre el juez se encontraría facultado para retrotraerse a un principio de preferencia constitucional, y solucionar directamente el caso respecto del cual actualmente se pronunciare, con independencia de cuanto se aleje de la solución original querida por la regla. Es lo que los autores llaman vulgarización del derecho por constitucionalización.

Por esa razón, la concurrencia de la aplicación directa de la Constitución con un recurso que tenga efectos erga omnes respecto de las decisiones sobre qué deben querer decir los conceptos constitucionales, produce un acercamiento gravitante al sistema anglosajón. Predicar un recurso de unificación de jurisprudencia que tenga efectos erga omnes abre las puertas para el gobierno de los jueces, que es todo lo contrario al autogobierno democrático manifestado en las leyes. Nuestro recurso de unificación de jurisprudencia debe ser entendido como uno que recoge solo uno de los objetivos del recurso de casación en el fondo, esto es, la finalidad monofláctica y uniformadora, entendida como ius constitutionis, y subordina completamente la otra finalidad del recurso de casación en el fondo, el cual es el ius litigatoris, entendida como el derecho del litigante a obtener una resolución favorable. Por lo tanto, no es sino un recurso de casación en el fondo a medias, que por mucho que persiga el interés público de la uniformidad en la jurisprudencia de los tribunales, no podría pretender obligatoriedad alguna so pena de quebrantar las bases republicanas sobre el que está fundado nuestro Estado de Derecho.

\section{BIBLIOGRAFÍA}

ACCATINO, Daniela. "Los afanes de la Interpretación Constitucional", en: Revista Derecho y Humanidades $\mathrm{N}^{\circ}$ 12. Santiago: Universidad de Chile, 2006.

ACKERMAN, Bruce. La nueva división de poderes. México: Fondo de Cultura Económica, 2007.

ATrIA, Fernando. "Las Circunstancias de la Derrotabilidad", en: Revista de Ciencias Sociales, N 45 . Valparaíso: Universidad de Valparaíso, 2000.

ATRIA, Fernando. "El derecho y la contingencia de lo político" [disponible en: http://descargas.cervantesvirtual. $\mathrm{com} /$ servlet/SirveObras/doxa].

ATrIA, Fernando. "El derecho y la contingencia de lo político", en: Revista del Centro de Estudios Públicos, 2000.

ATRIA, Fernando. "La improbabilidad de la jurisdicción", en: COUSO, Javier y ATRIA, Fernando. La Judicatura como organización. Santiago: Instituto de Estudios Judiciales, 2005 [ disponible en http://www.expansi$\mathrm{va.cl} /$ media/publicaciones/libros/pdf/5.pdf]

ATRIA, Fernando. "La ironía del positivismo jurídico" [disponible en: htrp://www.cervantesvirtual.com/servlet/ SirveObras/09259512077961540032268/028045.pdf].

ATRIA, Fernando. "Sobre la soberanía y lo político", en: Revista Derecho y Humanidades No 12. Santiago: Universidad de Chile, 2006.

BORDALI SALAMANCA, Andrés. "La unidad en la interpretación jurisdiccional de los derechos fundamentales: una tarea pendiente en el derecho chileno", en: Revista Chilena de Derecho, vol. 43, No 3. Santiago: Pontificia Universidad Católica de Chile, 2007. 
BUSH VENTUR, Tania. "Aproximaciones al fundamento de la jurisdiccionalidad del control jurisdiccional”, en: Revista Derecho y Humanidades $\mathrm{N}^{\circ}$ 12. Santiago: Universidad de Chile, 2006.

CORREA G., Rodrigo. "El gobierno judicial ante la Constitución", en: Revista de Estudios de la Justicia $\mathrm{N}^{\circ}$ 6. Santiago: Centro de Estudios de la Justicia, Universidad de Chile, 2005.

DwORKIN,. Ronald. "La lectura moral y la premisa mayoritarista", en: KOH, Harold Hongju y SLYE, Ronald C. (comp.). Democracia Deliberativa y Derechos Humanos. Editorial Gedisa, 2004.

DWORKIN, Ronald. Los Derechos en Serio. Barcelona: Editorial Ariel S.A., año 1999.

GARGARELLA, Roberto. La justicia frente al gobierno, sobre el carácter contramayoritario del poder judicial. Barcelona: Editorial Ariel S.A., 1996.

GARRIDO GOMEZ, María Isabel. "La predecibilidad de las decisiones judiciales", en: Ius et Praxis $15 \mathrm{~N}^{\circ} 1$, Talca, Universidad de Talca.

GUASTINI, R. "Variaciones sobre temas de Carlos Alchourrón y Eugenio Buligyn, derrotabilidad, lagunas axiológicas e interpretación”, en: Análisis Filosófico XXVI No 2, pp. 277-293, noviembre 2006.

HABERMAS, Jürgen. Facticidad y Validez. Madrid: Editorial Trotta, S.A. 1998.

Legarre, Santiago y Rivera, Julio César. "Naturaleza y dimensiones del stare decisis", en: Revista Chilena de Derecho, vol. $33 \mathrm{~N}^{\circ}$ 1. Santiago: Pontificia Universidad Católica, 2006.

Mouffe, Chantal. "Democracia y Pluralismo Agonístico", en: Revista Derecho y Humanidades N 12, p. 20. Santiago: Universidad de Chile, 2006.

NINO, Carlos Santiago. La Constitución de la Democracia Deliberativa. Barcelona: Editorial Gedisa, año 1997.

NOGUEIRA ALCALÁ, Humberto: "La independencia del poder judicial: una condición y garantía estructural del Estado Constitucional", en: Gaceta Juridica N³29, noviembre 2007.

PFEFFER URQUIAGA, Emilio. "La introducción del precedente. Un cambio revolucionario en nuestra cultura jurídica", en: Estudios Constitucionales, p. 11. Talca: Céntro de Estudios Constitucionales, Universidad de Talca, julio 2006.

Rousseau, J.J. El Contrato Social. Madrid: Editorial Alba, 1998.

RUIZ SCHNEIDER, Carlos. "Democracia y Liberalismo en Ronald Dworkin", en: Revista Derecho y Humanidades $\mathrm{N}^{\circ}$ 14, p. 26. Santiago: Universidad de Chile, 2008.

RuIZ-TAGLE, Pablo. "Análisis comparado de la función judicial", en: Derecho, Justicia y Libertad. Distribuciones Fontamara, México, 2002.

WALDRON, Jeremy. "Deliberación, desacuerdo y votación", en: KOH, Harold Hongju y SLYE, Ronald C. (comp.). Democracia Deliberativa y Derechos Humanos. Editorial Gedisa, 2004.

YÁÑEZ MONJE, Eduardo. "Comentarios acerca del concepto de empresa en el Código del Trabajo", en: Revista Chilena de Derecho del Trabajo y de la Seguridad Social, vol. 1. N 1. Santiago: Universidad de Chile, 2010. 